MD \# 7807

\title{
ONTOGENY OF HEPATIC AND PLASMA METABOLISM OF DELTAMETHRIN IN VITRO: ROLE IN AGE-DEPENDENT ACUTE NEUROTOXICITY
}

Sathanandam S. Anand, Kyu-Bong Kim, Stephanie Padilla, Srinivasa Muralidhara, Hyo J. Kim, Jeffrey W. Fisher and James V. Bruckner

Department of Pharmaceutical and Biomedical Sciences, College of Pharmacy, University of Georgia, Athens, Georgia 30602, USA (S. S. A., K-B. K, S. M., H. J. K. and J. V. B.); Department of Environmental Health Science, School of Public Health, University of Georgia, Athens, Georgia 30602, USA (J. W. F.); Cellular and Molecular Branch, Neurotoxicology Division, U.S. Environmental Protection

Agency, Research Triangle Park, NC, 27711, USA (S. P.) and Pharmacology Department, National Institute of Toxicological Research, Korea Food and Drug Administration, 5-Nokbun-dong,Eunpyung-gu, Seoul 122-704, South Korea (K-B, K) 
Running title: Age-dependent metabolism of DLM

Address correspondence to: Sathanandam S. Anand

Department of Pharmaceutical and Biomedical Sciences

College of Pharmacy

University of Georgia

Athens, Georgia 30602, USA

Tel \# 706-542-5401

Fax - 706-542-5358

Email: sanand@rx.uga.edu

Number of text pages: 31

Number of tables: 2

Number of figures: 7

Number of references: 40

Number of words in Abstract: 247

Number of words in Introduction: 686

Number of words in Discussion: 1536

Abbreviations:

AUC - area under the curve

DLM - deltamethrin

$\mathrm{CaE}$ - carboxylesterase

HPLC - high performance liquid chromatography

PBPK - physiologically based pharmacokinetic

PND - postnatal day 


\section{MD \# 7807}

\section{Abstract:}

Deltamethrin (DLM) is a relatively potent and widely used pyrethroid insecticide. Inefficient detoxification has been proposed to be the primary reason for the greater sensitivity of immature rats to DLM acute neurotoxicity. The objective of this study was to test this hypothesis by characterizing the age-dependency of DLM metabolism in vitro, as well as toxic signs and blood levels of the neurotoxic parent compound following administration of $10 \mathrm{mg} \mathrm{DLM} / \mathrm{kg}$ po in glycerol formal. Metabolism was quantified in vitro by monitoring disappearance of the parent compound from plasma [via carboxylesterases (CaEs)] and liver microsomes [via CaEs and cytochome P450s (CYPs)] obtained from 10-, 21- and 40-d-old (PND) male Sprague-Dawley rats. Mean $( \pm \mathrm{SE})$ intrinsic clearances $\left(\mathrm{V}_{\max } / \mathrm{K}_{\mathrm{m}}\right)$ in these respective age-groups by liver CYPs $(4.99 \pm 0.32,16.99 \pm 1.85$ and $38.45 \pm 7.03)$ and by liver CaEs $(0.34 \pm 0.05,1.77 \pm 0.38$ and $2.53 \pm 0.19)$ and plasma CaEs $(0.39 \pm 0.06,0.80 \pm 0.09$ and $2.28 \pm 0.56)$ increased significantly $(\mathrm{p} \leq 0.05)$ with age, due to progressive increases in $\mathrm{V}_{\max }$. Intrinsic clearance of DLM by plasma CaEs and liver CYPs reached adult levels by $40 \mathrm{~d}$, but clearance by liver CaEs did not. Hepatic CYPs played the predominant role in DLM biotransformation in young and adults. The incidence and severity of neurotoxic effects varied inversely with age. Correspondingly, blood DLM AUCs and Cmaxs progressively decreased with increasing age. Internal exposure to DLM (blood AUCs) was closely correlated with toxic signs (salivation and tremors). The present study provides evidence that immature rats' limited metabolic capacity contributes to elevated systemic exposure and ensuing neurotoxic effects of DLM. 


\section{MD \# 7807}

Pyrethroid insecticides are widely used in forestry, agriculture, veterinary and human medicine, and household pest control (ATSDR, 2003; Soderlund et al., 2002). Pyrethroids did account for $\sim 25 \%$ of the worldwide insecticide market (Casida and Quistad, 1998). Use of pyrethroids in the U.S. has substantially increased since 1998, due the decreased use of organophosphorus pesticides. Exposures to pyrethroids have been documented in a several potentially sensitive subpopulations, including pregnant women, infants and children (Berkowitz et al; 2003; Heudorf et al., 2004; Whyatt et al., 2002; Yanez et al., 2002). Heudorf et al. (2004) measured pyrethroid metabolites in the urine of 1,177 persons without apparent exposure in Germany.

Pyrethroids are divided into two categories, Types $\mathrm{I}^{1}$ and $\mathrm{II}^{2}$, based on their chemical structure and toxicity (Glickman and Casida, 1982). DLM, a Type II pyrethroid, is a relatively potent neurotoxicant. Major signs of acute poisoning include salivation, hyperexcitability, chloroeoathetosis and seizures. Interaction with neuronal voltage-sensitive sodium channels is the primary mode of action of DLM (Soderlund et al., 2002). The parent compound is believed to be the proximate toxicant, as demonstrated by correlation of brain DLM levels with the onset of symptoms of poisoning in rats (Rickard and Brodie, 1985). Intracerebral injection of DLM produced signs of neurotoxicity within a min or less in mice (Lawrence and Casida, 1982).

Immature animals are more sensitive to the acute neurotoxicity of pyrethroids than adults. The susceptibility of rat pups to cypermethrin (Type II) and permethrin (Type I) lethality was found to be inversely related to age (Cantalamessa, 1993). The author speculated that incomplete development of detoxification enzymes was probably responsible for the age-dependency, though his experiments with monooxygenase and esterase inhibitor pretreatments were inconclusive. Sheets et al. (1994) also noted that preweanling pups were much more susceptible to acute DLM toxicity than adults; oral $\mathrm{LD}_{50}$ s for 11-, 21- and 72-d-old rats were reported to be 5, 11 and $81 \mathrm{mg}$ 


\section{MD \# 7807}

$\mathrm{DLM} / \mathrm{kg}$. At the time of death, comparable brain DLM concentrations were present in weanling and adult rats that received 12 and $80 \mathrm{mg}$ DLM/kg po, respectively. Sheets (2000) proposed that the greater sensitivities of rat pups to lethal doses of Type II pyrethroids were due to limited metabolic capacity, though no data on the age-dependency of biotransformation of pyrethroids were located.

DLM has been studied in adults, but information on its metabolism and disposition in immature laboratory animals and humans is very limited. DLM appeared to be rapidly, but poorly absorbed from the gastrointestinal (GI) tract of adult rats, disparately distributed in different brain regions, and oxidized in the liver to 4'-hydroxy DLM (Anàdon et al., 1996). Gray and Rickard (1981) observed substantially higher radioactivity levels in plasma than in brain over time following iv injection of adult rats with ${ }^{14} \mathrm{C}$-labeled DLM. Levels in fat were significantly higher than in other tissues. DLM and other pyrethroids are metabolized in adult male rats and mice by ester cleavage and by cytochome P450 (CYP)-catalyzed hydroxylation, with subsequent glucuronidation and sulfation (Fig. 1) (Ruzo et al., 1978, 1979; Soderlund and Casida, 1977). Pyrethroids with a cyano group (e.g., DLM) were the least prone to ester hydrolysis and CYP oxidation. Anand et al. (2005) recently reported that adult male rat hepatic CYPs, notably CYP1A1 and CYP1A2, play a more important role than hepatic microsomal and plasma carboxylesterases (CaEs) in biotransformation of DLM in vitro. Relatively low intrinsic clearance by plasma CaEs indicated that detoxification in the bloodstream should be modest compared to that in the liver.

A major objective of the present study was to characterize the ontogeny of DLM metabolism in the maturing male Sprague-Dawley rat. One aim was to conduct a qualitative and quantitative in vitro comparison of DLM biotransformation in the maturing rat with that observed previously in the adult (Anand et al., 2005). A related aim was to assess the influence of maturation on in 
MD \# 7807

vivo blood DLM time-profiles and manifestations of neurotoxicity. The in vitro metabolic rate constants and in vivo blood DLM time-profiles will subsequently be utilized for construction of a physiologically-based pharmacokinetic (PBPK) model to predict target organ dosimetry of DLM in immature rats and in children. 


\section{MD \# 7807}

\section{Materials and Methods}

Chemicals. DLM ((S)-alpha-cyano-3-phenoxybenzyl-(1R,cis)-2,2-dimethyl-3-(2,2dibromvinyl)-cyclopropanecarboxylate) was obtained from ChemService (Westchester, PA, 98\% pure). Acetonitrile (HPLC-grade) was procured from Burdick and Jackson (Muskegon, MI). Tetra isopropyl pyrophosphoramide (isoOMPA) was purchased from Sigma Chemical Co (St. Louis, MO). All other chemicals were of analytical grade.

Animals. Timed-pregnant (GD12) and adult male Sprague-Dawley (SD) rats were obtained from Charles River Inc. (Raleigh, NC). The rats were housed individually and allowed water and food (Purina Rat Chow 5001; Purina, St. Louis, MO) ad libitum. The AAALAC-approved animal care facility was maintained at $72 \pm 2^{\circ} \mathrm{F}$ and $50 \pm 10 \%$ humidity with a 12 -h light/dark cycle. The experimental protocol was reviewed and approved by the University of Georgia Animal Care Committee. The day each litter was born was considered postnatal day 0 (PND0). On PND3, pups were sexed and a total of 8 pups housed with each dam. The pups (largely males) were housed with dams until sacrifice on PND10 or upon weaning (PND21). The remaining pups were housed separately (5/cage) until PND40, when they were utilized. Only male rats were used for the DLM metabolism workups for each age-group.

Plasma and Liver Microsome Preparation. Male rat pups of different ages (10-, 21-, and 40-d) were sacrificed by cervical dislocation, and blood and liver samples collected. Blood was drawn by cardiac puncture and centrifuged at 2500xg for $10 \mathrm{~min}$ in a Microfuge $22 \mathrm{R}$ centrifuge (Beckman Coulter $^{\mathrm{TM}}$, Atlanta, GA) to obtain plasma. The plasma was frozen at $-80^{\circ} \mathrm{C}$ until the time of use. It was necessary to combine the livers and plasma of 12 - 14 PND10 pups (interlitter pool) and $7-8$ PND21 pups (intra-litter pool) to obtain a total of $\sim 5 \mathrm{~g}$ liver and $2.5 \mathrm{ml}$ plasma. Four separate pooled liver and plasma composites per age-group were obtained for 


\section{MD \# 7807}

analyses. The liver and plasma of each PND40 rat were adequate to yield $5 \mathrm{~g}$ tissue and $2.5 \mathrm{ml}$ plasma per animal.

Liver microsomes were prepared by differential centrifugation. Each 5-g portion of fresh liver was homogenized in $25 \mathrm{ml}$ of cold $0.02 \mathrm{M}$ Tris-KC1 buffer, $\mathrm{pH} 7.4$, using a Teflon ${ }^{\mathrm{TM}} / \mathrm{glass}$ tissue homogenizer. The homogenized liver was centrifuged using a Beckman Avante (JE25) centrifuge (Palo Alto, CA) for $30 \mathrm{~min}$ at $4^{\circ} \mathrm{C}$ at $12000 \mathrm{xg}$. The supernatant was collected and centrifuged using a Beckman Coulter Optima XL-100K ultracentrifuge (Fullerton, CA) at $4^{\circ} \mathrm{C}$ at 105,000xg for $60 \mathrm{~min}$. The microsomal pellet was resuspended in Tris-KC1, pH 7.4 buffer and frozen at $-80^{\circ} \mathrm{C}$. Protein content of the microsomes was measured by a standard colorimetric procedure. Because the liver microsomes were resuspended in a volume of buffer the same as the original volume of liver, enzyme activities measured in each $\mathrm{ml}$ of suspension could be expressed per g liver (Anand et al., 2005).

In Vitro Metabolism of DLM. The kinetics of DLM metabolism in plasma and hepatic microsomes was evaluated by measuring the rate of disappearance of parent compound. Hydroxylated metabolites of DLM are not commercially available to use as standards. Initial experiments (data not shown) were conducted to verify the optimal incubation conditions for each assay (plasma CaEs, liver CaEs and liver CYPs). Disappearance of DLM was linear with respect to time and tissue concentration over the DLM concentration ranges relevant to this study. Separate incubations were performed for plasma and liver microsomal CaEs- and CYPs-mediated metabolism. In vitro incubations of each liver or plasma sample from the 10-, 21- and 40-d-old pups were conducted concurrently. Incubation conditions varied with the animal donors' age, as described below. The velocity (Vo) of each reaction was expressed as nmol DLM disappearance/h/g liver or $\mathrm{ml}$ plasma. CaE metabolism was characterized using the inhibitor isoOMPA (1 $\mathrm{mM}$ in plasma and $24 \mathrm{mM}$ in liver, final concentration). Details on the choice and 


\section{MD \# 7807}

efficacy of the $\mathrm{CaE}$ inhibitor (i.e., isoOMPA) have been described in our previous report (Anand et al., 2005). NADPH-dependent metabolism was considered as CYP-mediated detoxification.

Plasma Metabolism of DLM. Various concentrations (2, 10, 20, 100 and $200 \mu \mathrm{M}$ final) of DLM were incubated at $37^{\circ} \mathrm{C}$ with $500 \mu \mathrm{l}$ of Tris-HC1 buffer (pH 7.4)-diluted plasma (40\% for PND10 and 30\% for PND21 and 40). The incubation times were $120 \mathrm{~min}$ for PND10 and 21 and $60 \mathrm{~min}$ for PND40. One set of plasma samples was preincubated with isoOMPA for $1 \mathrm{~h}$ for CaE inhibition (Anand et al., 2005) before addition of DLM. The reaction was initiated by adding 500 $\mu l$ of diluted ice-cold plasma (with or without isoOMPA) to $5 \mu$ l of various DLM concentrations (in acetonitrile, never more than $1 \%$ of total volume). Similar incubations were conducted with Tris-HC1 buffer, which served as a non-enzymatic control. After respective incubation periods, $1.5 \mathrm{ml}$ of acetonitrile were added for DLM extraction and analysis, as described below. The difference in DLM concentrations, between tubes with and without isoOMPA, was considered to be due to CaE-mediated metabolism.

\section{Liver Microsomal Metabolism of DLM.}

Liver CaEs: Liver microsomes from PND10 (1:2 dilution, $10 \mathrm{mg}$ protein/ml), PND21 (1:5 dilution, $\sim 4 \mathrm{mg}$ protein/ml) and PND40 (1:10 dilution, $\sim 2 \mathrm{mg}$ protein/ml) pups were preincubated with or without $10 \mu \mathrm{l}$ isoOMPA for $1 \mathrm{~h}$ at room temperature. One $\mathrm{ml}$ of ice-cold microsomes with or without isoOMPA was added to $10 \mu \mathrm{l}$ of a series of concentrations of DLM $(2,10,20,100$ and $200 \mu \mathrm{M}$ final) to initiate the reaction. PND10 microsomes were incubated for $60 \mathrm{~min}$, while PND21 and 40 microsomes were incubated for $30 \mathrm{~min}$ at $37^{\circ} \mathrm{C}$. A buffer control was included to account for background hydrolysis. At the end of the incubation periods, $3 \mathrm{ml}$ of acetonitrile were added to the incubation mixture to stop the reaction and to extract the DLM. DLM extraction and analysis are described below. The difference in DLM concentrations 


\section{MD \# 7807}

between tubes with and without isoOMPA was considered to be due to CaE-mediated metabolism.

Cytochrome P450s: DLM metabolism by CYPs was assessed by incubating $1 \mathrm{ml}$ of Tris-HC1 buffer ( $\mathrm{pH}$ 7.4)-diluted microsomes (4 mg protein/ml; for PND10 and 21; $1 \mathrm{mg}$ protein/ml for PND40) with $10 \mu \mathrm{l}$ of a series of DLM concentrations (2 to $200 \mu \mathrm{M}$ final) with and without NADPH (1.2 mM, final) at $37^{\circ} \mathrm{C}$. PND10 microsomes were incubated for $30 \mathrm{~min}$, while PND21 and 40 microsomes were incubated for $15 \mathrm{~min}$. The reaction was initiated by adding the ice-cold microsomes. A buffer control was also included to account for non-enzymatic hydrolysis. At the end of the incubation period, $3 \mathrm{ml}$ of acetonitrile were added to the incubation mixture to terminate the reaction and to extract the DLM. DLM extraction and analysis are described below. The difference in DLM concentrations between tubes with and without NADPH was considered to be due to CYP-mediated metabolism.

DLM extraction and HPLC assay. Addition of acetonitrile to biological samples terminated enzymatic reactions by protein denaturation and precipitation. The tubes were vortexed for 5 min and centrifuged for $10 \mathrm{~min}$ at 2500xg (Beckman Coulter ${ }^{\mathrm{TM}}$, Atlanta, GA). Two hundred $\mu \mathrm{l}$ of supernatant were transferred to a HPLC vial, from which $40 \mu 1$ were injected onto the HPLC column. Duplicate injections were made of all samples, and an average of the two injections was used for calculation of the DLM concentration.

DLM in plasma and microsomes was measured according to the high performance liquid chromatography (HPLC) method of Kim et al. (2005) (submitted for publication). The HPLC system was manufactured by Waters Inc. (Milford, MA) and consisted of a Waters 717 autosampler, 515 pump and 2487 UV detector. The columns used were a Waters Spherisorb ${ }^{\mathrm{TM}}$ 5- $\mu$ m C8 column (150 mm long x $4.6 \mathrm{~mm}$ internal diameter) and a Waters Spherisorb ${ }^{\mathrm{TM}} \mathrm{S} 5 \mathrm{C} 8$ 


\section{MD \# 7807}

guard column (10 mm long x $4.6 \mathrm{~mm}$ internal diameter). The mobile phase was 70:30 acetonitrile $/ 1 \%$ sulfuric acid at a flow rate of $1 \mathrm{ml} / \mathrm{min}$. Peak heights were quantified at $230 \mathrm{~nm}$ by the external standard technique using standard solutions of DLM (5 ng to $10 \mu \mathrm{g}$ ).

Since we have recently measured and reported (Anand et al., 2005) metabolic rate constants for adult rats (PND90), these data were included in the present report. Nonetheless, in vitro incubations of PND90 liver microsomes and plasma were performed along with other ages with the lowest $(2 \mu \mathrm{M})$ and highest $(200 \mu \mathrm{M})$ DLM concentrations to determine whether there was significant day-to-day variability in experimental results. This proved not be the case, so the previously published PND90 data were used here to compare with immature rat data.

Assessment of toxic signs and blood DLM levels in vivo. The objective of this phase of the study was to assess the age-dependency of toxicity and of internal DLM exposure following administration of equivalent dose of DLM to young and adult rats, and so in vivo findings could be related to the in vitro metabolism data. Ten-, 21-, 40- and 90-d-old male SD rats received 10 $\mathrm{mg}$ DLM/kg in glycerol formal by gavage. This dose was selected on the basis of our own preliminary studies and the LD50 data of Sheets et al. (1994). Since there are no widely accepted biochemical markers for pyrethroid neurotoxicity (Soderlund et al., 2002), our rats were monitored for commonly-manifested signs: salivation, tremors and lethality. The signs were evaluated $(\mathrm{n}=4)$ periodically for up to $6 \mathrm{~h}$ after DLM exposure. The salivation was graded using the following scoring system: 0 - no saliva; 1 - wet area around the mouth and nose (mild); 2 wet area around the mouth, nose and some on the neck (moderate); 3 - entire mouth, nose and neck covered with saliva (severe). The severity of tremors was graded as follows: 0 - no tremor; 1 - slight tremor or loss of balance after being picked up (mild); 2 - constant tremor (moderate); 3 


\section{MD \# 7807}

- violent tremor and no voluntary control of movement (severe). The observer was blinded to the treatment of the rats.

Rats ( $n=3$ or 4 ) of each age were serially sacrificed from 15 min to $24 \mathrm{~h}$ post dosing to collect blood and selected tissues for analyses of DLM. Because of $100 \%$ mortality, it was possible to collect samples only up to 6 and $12 \mathrm{~h}$ for PND10 and 21 animals, respectively. The blood samples were processed immediately for DLM analysis as described by Kim et al. (2005). Only blood DLM profiles and toxicity data are presented here. The tissue DLM profiles will be reported elsewhere.

Data Analyses. Microsomal and plasma incubations were conducted with four pooled or individual samples for each age-group. The Michaelis-Menten metabolic rate constants $\left(\mathrm{V}_{\max }\right.$ and $\mathrm{K}_{\mathrm{m}}$ ) were calculated by nonlinear regression using Prism (3.03). Regression coefficients $\left(\mathrm{r}^{2}\right)$ to corroborate age-dependent internal DLM exposure to toxic signs were also computed using the same software. Areas under blood DLM concentration versus time curves (AUCs) were calculated by the trapezoidal rule. The metabolic rate constants (Figs. 2-5 and Table 1) were initially analyzed by a global, repeated ANOVA using Km, Vmax, and intrinisic clearance as the dependent variables, and age and enzyme (i.e., plasma $\mathrm{CaE}$, liver $\mathrm{CaE}$ or liver $\mathrm{CYP}$ ) as the independent variables. Where significant interactions were noted between the dependent variables, step down ANOVAs were conducted on each dependent variable against age and enzyme activity. Based on the interactions, further step-down ANOVAs were conducted with subsequent comparisons between different ages or different enzymes made using a TukeyKramer post hoc test. All analyses were conducted using StatView (SAS, Cary, NC; version 5.0.1). Statistical significance at all levels of analysis was considered to be $p \leq 0.05$. All data are presented as mean $\pm \mathrm{SE}$. 


\section{MD \# 7807}

\section{Results}

Plasma Metabolism by CaEs. The age-dependency of DLM biotransformation by plasma $\mathrm{CaEs}$ in rats is illustrated in Fig. 2. The rate of DLM metabolism increases with the age, as reflected by the progressive increases in $\mathrm{V}_{\max }$. The calculated $\mathrm{V}_{\max }$ and $\mathrm{Km}$ values are presented in Table $1 . \mathrm{V}_{\max }$ values of 90 -d-old adults are $\sim 6.8$ and 3.7 times higher $(\mathrm{p} \leq 0.05)$ than for PND10 and 21 pups, respectively. The PND10 and 21 Vmax values are not statistically different, nor are the PND40 and 90 Vmax values. $\mathrm{K}_{\mathrm{m}}$ values remain relatively constant from PND10 to 40 . The mean PND90 Km appeared to be somewhat higher, but the elevation was not statistically significant. Intrinsic clearance increases significantly with age, reaching adult levels by PND40. Addition of isoOMPA almost completely inhibited DLM metabolism in each age-group (Fig. 2 insert), confirming the role of CaEs in DLM biotransformation in plasma of immature rats.

Hepatic Microsomal Metabolism by CaEs. DLM metabolism by liver microsomal CaEs (Fig. 3) is age-dependent, but its developmental pattern differs in some respects from that of plasma CaEs. The male rat liver CaE metabolic capacity increases significantly with age (Table 1). There is roughly a 5-fold increase $(\mathrm{p} \leq 0.05)$ in liver CaE activity between PND10 and 21 , in contrast to the lack of significant rise in plasma $\mathrm{CaE}$ activity during this period. The liver microsomal $\mathrm{V}_{\max }$ for PND40 rats is significantly higher than for PND10 ( 12-fold) and 21 rats ( 2.6-fold). Nevertheless, the PND40 $\mathrm{V}_{\max }$ is only $15 \%(\mathrm{p} \leq 0.05)$ of that in 90 -d-old adults (Table 1). $\mathrm{K}_{\mathrm{m}}$ values remain relatively constant during maturation. Intrinsic clearance in the PND90 adults was significantly higher than in the immature age groups. The PND21 and 40 clearances were not significantly different from one another, but were higher than in PND10 pups. The addition of isoOMPA completely inhibited DLM metabolism in each immature agegroup at all the concentrations studied (Fig. 3 insert). 


\section{MD \# 7807}

Hepatic Microsomal Metabolism by CYPs. Figure 4 presents age-dependent metabolism of DLM by CYP. The maximal velocity of DLM detoxification by liver CYPs doubles between PND10 and 21, and triples again by PND40 (Table 1). The net result is almost a 7-fold increase in metabolic capacity between PND10 and 40. As with plasma and liver microsomal CaEs, affinity of CYP for DLM does not vary with age of the immature rats, but the Km of adult rats is significantly higher than those of the young rats. The Vmax and Km of the PND40 rats are each only about one-half those of the adults, so intrinsic clearance does not change between 40 and 90 d (Table 1). Statistically significant increase in intrinsic clearance is noted with increasing age until PND40.

Findings of the age-dependency of plasma and liver microsomal CaE-catalyzed and liver microsomal CYP-mediated intrinsic clearance of DLM are presented graphically in Fig. 5. The efficiency of liver microsomal and plasma CaEs in metabolizing DLM is comparable in the 10-, 21- and 40-d-old rats (Fig. 5A). In contrast, Anand et al. (2005) found that liver microsomal CaEs of adult male SD rats were more efficient $(\mathrm{p} \leq 0.05)$ than plasma CaEs in biotransformation of DLM, as is evident in Fig. 5A. It is worthy of note again that liver CaE activity of PND40 pups is only about $15 \%$ of that in PND90 adults (Fig. 5B). CYP-catalyzed DLM metabolism is substantially greater than metabolism by plasma and/or hepatic microsomal CaEs at each developmental stage (Fig. 5A). Liver CYP and plasma CaE activities increase to $\sim$ adult levels between d 10 and 40 in the maturing male SD rats (Fig. 5B). The relatively modest increase in liver microsomal $\mathrm{CaE}$ activity during this developmental period appears to be primarily responsible for the 40-d-old rats' inability to attain adult DLM metabolic capacity (Fig. 5B).

\section{DLM Internal Exposure and Neurotoxicity Following In Vivo Dosing. Blood DLM} concentration versus time profiles are plotted in Figure 6A. DLM is rapidly absorbed from the GI tract. Blood levels appear to peak around $1 \mathrm{~h}$ after the oral dosing in the 40- and 90-d-old rats, but 


\section{MD \# 7807}

plateau in the 10- and 21-d-old rats. Pronounced toxicity likely contributed to the unusual kinetic profiles in the latter two groups. AUCs are truncated at 6 and $12 \mathrm{~h}$, due to the death of each PND10 and 21 animal soon after these times, respectively (Fig. 6B). In each instance, the AUCs vary inversely with age. Age-dependent decreases in blood AUCs were statistically significant except the decrease noted between PND40 and 90. The Cmaxs also appeared to progressively decrease with increasing age, though the PND21, 40 and 90 values were not statistically different from one another (Fig. 6C).

The severity of signs of DLM neurotoxicity was inversely related to age (Table 2). It is evident that the most pronounced salivation and tremors were experienced by the youngest rats. Both manifestations of neurotoxicity increased over time following dosing in the PND10 and 21 animals. This was particularly true for tremors. All of the PND10 and 21 rats died between 6-8 $\mathrm{h}$ and 12-16 h, respectively. None of the PND40 or 90 rats succumbed. No tremors were observed in the members of either older group. Salivation was mild (PND90) to moderate (PND40) and lasted only 2 to $3 \mathrm{~h}$.

There was concordance between the severity of acute neurotoxic signs and the magnitude of systemic DLM exposure. Total scores were obtained for salivation and for tremors by summing the 1-, 2-, 3-, 4-, and 6-h scores in Table 2 for each age-group. These total scores for each toxic sign were plotted against the groups' blood DLM AUCs (0-6 $\mathrm{h}$ for PND10 and 0-12 $\mathrm{h}$ for PND21, 40 and 90 rats) (Fig. 7). There was a good correlation between AUCs and severity of salivation $\left(r^{2}-0.87\right)$ and between AUCs and severity of tremors $\left(r^{2}-0.90\right)$. Lower correlation coefficients were obtained when relating to the total toxicity scores to Cmax values $\left(\mathrm{r}^{2}-0.63\right.$ for salivation vs Cmax; $\mathrm{r}^{2}-0.70$ for tremors vs Cmax) (data not shown). 


\section{MD \# 7807}

\section{Discussion}

An important aim of this study was to test the hypothesis that inefficient metabolic detoxification is a contributing factor to the greater susceptibility of neonatal and weanling rats to acute DLM neurotoxicity. Sheets et al. (1994) clearly showed that DLM toxicity varied with age of immature Long-Evans rats. In the present study, 10- and 21-d-old male SD rats gavaged with $10 \mathrm{mg} \mathrm{DLM} / \mathrm{kg}$ exhibited pronounced salivation and tremors leading to $100 \%$ mortality between $6-8 \mathrm{~h}$ and $12-16 \mathrm{~h}$ in the PND10 and 21 groups, respectively. PND40 and 90 rats receiving the same dose experienced only transient salivation, and all the rats survived. Decreased internal exposure to DLM during maturation, as evidenced by AUCs and Cmaxs (Figs. 6B and C) paralleled the severity of poisoning (Table 2). AUC (Fig. 7) showed a higher degree of correlation with toxic signs than did Cmax (data not shown). DLM metabolism in vitro by plasma and liver CaEs and hepatic CYPs exhibited progressive increases with maturation (Table 1). These findings strongly support the aforementioned hypothesis.

There has been a paucity of recent data on the metabolism and systemic disposition of DLM and other pyrethroids, despite their rapidly expanding use in the U.S. and other countries. This is particularly true of immature laboratory animals and humans. Anand et al. (2005) identified and clarified the relative contributions of liver CYPs and liver and plasma CaEs to DLM metabolism in adult, male SD rats. The current study is the first to characterize the ontogeny of DLM metabolism. The age-dependent increases in the capacity of plasma CaEs and CYPs to detoxify DLM reach adult levels by $40 \mathrm{~d}$, but the contribution of liver CaEs is more limited in the PND40 rats than in adults (Fig. 5). These data are in agreement with the agedependent reductions in blood DLM levels (Fig. 6) and toxic signs (Table 2). The findings should be generally applicable to other pyrethroids, though the extent to which these compounds are hydrolyzed and oxidized depends upon their isomerization and substitutions (Soderlund and 


\section{MD \# 7807}

Casida, 1977). Age-, sex- or species-dependent differences may assume greater importance in the detoxification of pyrethroids that are designed to be metabolically stable than would be the case with very rapidly metabolized congeners.

Plasma and hepatic microsomal CaEs that cleave DLM exhibit different developmental profiles. Intrinsic clearance of DLM by plasma CaEs nearly matches adult levels by PND40. Intrinsic clearance by liver CaEs at PND40 is only about 15\% of that in adult rats (Fig. 5), suggesting that liver CaEs undergo substantial maturational changes between PND40 and 90. Investigations of the heightened sensitivity of young rats to acute organophosphate toxicity also reveal age-related increases in the activities of plasma and liver CaEs, but most of these developmental data are limited to preweanling rats (Karanth and Pope, 2000; Moser et al., 1998). Sterri et al. (1985) report that plasma CaE activity in male Wistar rats reaches adult levels by PND30, but that liver CaE activity is still only $70-80 \%$ of that in adults. In contrast, Morgan and coworkers (1994) reported that liver CaE activity reached adult levels by $42 \mathrm{~d}$, but these researchers evaluated just two isozymes (hydrolases A and B). The relationship of these isozymes to the metabolism of DLM is not known. The significantly lower metabolic capacity of PND40 than PND90 liver CaEs than (Fig. 5) apparently reflects the relatively slow development of hepatic CaEs that cleave DLM.

There are apparently qualitative, as well as marked quantitative age-related differences in both rat plasma and liver CaEs that metabolize DLM (Table 1). There is relatively little variation in plasma or liver $\mathrm{K}_{\mathrm{m}}$ values during this developmental period. Bell and Ecobichon (1975) used $\alpha$ naphthyl acetate as a substrate to monitor $\mathrm{CaE}$ activity in the $\mathrm{S} 9$ liver supernatant of unsexed Wistar rats, ranging in age from 3 days prepartum to PND35. These researchers report a progressive decrease in $K_{m}$ from prepartum day 3 to PND 14, followed by a progressive rise through PND 35. Adult $\mathrm{K}_{\mathrm{m}}$ values were not reported. We, like Bell and Ecobichon (1975), 


\section{MD \# 7807}

observed marked increases in $\mathrm{V}_{\max }$ values throughout maturation. The substantial increases in intrinsic clearance of DLM were thus largely quantitative in nature. CaEs are group of substratespecific isozymes that are initially synthesized as precursors, which undergo structural modifications to yield the mature forms (Satoh and Hosokawa, 1998). Maturational changes associated with different isoforms and structural modifications may contribute to the modest qualitative and marked quantitative changes, as well as the differences in the developmental profile we observed in rat plasma and liver CaEs that metabolize DLM.

DLM metabolism in vitro by CYP is substantially greater than by plasma or liver CaEs in maturing male S-D rats (Table 1), as is the case in adults (Anand et al., 2005). This finding is supported by the results of an in vivo toxicity and metabolism study by Ruzo et al. (1979). These investigators found that pretreatment of mice with tributyl phosphorothionate, an esterase inhibitor, decreased urinary DLM metabolite excretion and also decreased the LD50 by 2-fold. Pretreatment of mice with piperonyl butoxide, a CYP inhibitor, inhibited metabolite excretion and produced a 3- to 5-fold decrease in $\mathrm{LD}_{50}$. Age-dependent increase in the intrinsic clearance by CYP in the current study was mainly due to increases in Vmax, not $\mathrm{Km}$. Intrinsic clearance by CYP reached adult levels by PND40, but adult $\mathrm{V}_{\max }$ and $\mathrm{K}_{\mathrm{m}}$ values were still significantly higher than PND40 values. The differences between 40 and 90 d may be associated with maturational changes in the CYPs associated with DLM biotransformation.

The identity of the CYP enzyme(s) that metabolize DLM has not been thoroughly investigated, although CYP1A1/2 and CYP2B1/2 are implicated. Using commercially available rat CYP enzymes, Anand et al. (2005) found that CYP1A1 and CYP1A2 were quite effective, and CYP2C11 exhibited modest activity in transforming DLM in vitro. Dayal et al. (1999) reported induction of CYP1A1/2 and CYP2B1/2 activities in liver following repeated (7-, 15- or 21-d) exposures to DLM. While reports on developmental changes (Atterberry et al., 1997; 


\section{MD \# 7807}

Gebremichael et al., 1995) of CYP1A1/2 and CYP2B1/2 activities are contradictory, ontogeny of DLM metabolism (Table 1) is not in accordance with the developmental changes of these enzymes. The possible reasons could be: 1) ethoxyresorufin $O$-deethylase and pentoxyresorufin $O$-dealkylase are usually considered to be catalyzed by CYP1A1/2 and CYP2B1/2, respectively, but other CYPs (i.e., CYP2C6 and 2C11) also contribute to deethylase and dealkylase activities (Kobayashi et al., 2002); and 2) there is no consensus on constitutive protein expression of CYP1A1/2 and CYP2B1/2 in rats (Agarwal and Shapiro 2003; de Waziers et al., 1990).

We did recently find that among the commercially available human CYP enzymes, CYP1A1, 1A2 and 2B6 were capable of metabolizing DLM (unpublished data). This suggests that the same enzymes could metabolize DLM in rats and humans. Constitutive CYP1A1 expression is often undetectable in adult human liver, and the developmental profile of CYP2B6 is largely unknown (Hines and McCarver, 2002). Sonnier and Cresteil (1998) demonstrated that CYP1A2 expression was absent in the liver of human neonates, gradually increased in infants, but was still only onehalf that in adults. While human CaEs that metabolize DLM have not yet been identified, a limited study of the maturational expression of human liver CaEs showed that activity in 5 infants $<2$ years old was not significantly lower than 5 adults (Pope et al., 2005). There may well be qualitative and quantitative interspecies differences in enzymes involved in DLM biotransformation. Nevertheless, the general deficit in CaEs and CYPs in the more immature humans and rodents suggest that these age-groups of both species will be particularly susceptible to acute DLM neurotoxicity.

In summary, the age-dependent increase in the DLM metabolism in vitro is consistent with the age-dependent decreases in the blood DLM levels and toxicity in vivo. Nevertheless, it should be recognized that age-dependent pharmacokinetic factors other than metabolism may also affect the bioavailability of DLM and the magnitude of its adverse effects. Preweanling rats 
MD \# 7807

are shown to have relatively high GI absorption rates (Hoffman, 1982; Naylor and Harrison, 1995). P-glycoprotein, which may play a role as an efflux transporter of pyrethroids (Bain and LeBlanc, 1996; Buss et al., 2002) have been found to be deficient in young mice (Mahmood et al., 2001). Extensive absorption and/or decreased efflux from the GI tract of young could contribute to the higher internal exposure and toxicity of DLM. Adult rats have larger amounts of body fat than perinatal animals. This may contribute to greater deposition of the highly lipophilic compound in the young animal's brain, as could an ineffectual blood-brain barrier. Srinivas et al. (2004) report that P-glycoprotein expression, relatively high levels of esterases and phosphatases, and pharmacodynamic effects are all responsible for resistance of moth larvae, a relatively simple organism, to pyrethroids. Investigations of the potential role of such age-dependent processes in appropriate mammalian species should improve our understanding of their relative importance, as well as the applicability of different species to children's risk assessments. The metabolic parameters determined here are being used in construction of a PBPK model for DLM in immature rats. Other key input parameters can be incorporated as they are identified. PBPK models, in turn, can be useful in informing the investigator of processes or parameters that deserve attention. 
MD \# 7807

\section{Acknowledgements}

The authors thank Dr. Kevin Crofton and Dr. Mike DeVito for critical review of an earlier version of the manuscript. The authors also thank Dr. Catherine White for her input in the in vivo experiments. 


$$
\text { MD \# } 7807
$$

\section{References}

Agrawal AK and Shapiro BH (2003) Constitutive and inducible hepatic cytochrome P450 isoforms in senescent male and female rats and response to low dose phenobarbital. Drug Metab. Dispos 31: 612-619.

Anàdon A, Martinez-Larranaga MR, Fernandez-Cruz ML, Diaz MJ, Fernandez MC, and Martinez MA (1996) Toxicokinetics of deltamethrin and its 4'-HO-metabolite in the rat. Toxicol Appl Pharmacol 141: 8-16.

Anand SS, Bruckner JV, Haines WT, Muralidhara S, Fisher JW, and Padilla S (2005) Characterization of deltamethrin metabolism by rat plasma and liver microsomes. Toxicol Appl Pharmacol In press.

ATSDR (Agency for Toxic Substances and Disease Registry) (2003). Toxicological Profile pyrethrins and pyrethroids. Atlanta, GA:. http://www.atsdr.cdc.gov/toxprofiles/tp155.html

Atterberry TT, Burnett WT, and Chambers JE (1997) Age-related differences in parathion and chlorpyrifos toxicity in male rats: Target and nontarget esterase sensitivity and cytochrome P450-mediated metabolism. Toxicol Appl Pharmacol 147: 411-418.

Bain LJ and LeBlanc GA (1996) Interaction of structurally diverse pesticides with the human MDR1 gene product P-glycoprotein. Toxicol Appl Pharmacol 141: 288-298.

Bell JU and Ecobichon DJ (1975) The development of kinetic parameters of hepatic drugmetabolizing enzymes in perinatal rats. Can J Biochem 53: 433-437.

Berkowitz GS, Obel J, Deych E, Lapinski R, Godbold J, Liu Z, Landrigan PJ, and Wolff MS (2003) Exposure to indoor pesticides during pregnancy in a multiethnic, urban cohort Environ Health Perspect 111: 79-84. 


\section{MD \# 7807}

Buss DS, McCaffery AR, and Callaghan A (2002) Evidence for p-glycoprotein modification of insecticide toxicity in mosquitoes of the Culex pipiens complex. Med Vet Entomol 16: 218222.

Cantalamessa F (1993) Acute toxicity of two pyrethroids, permethrin, and cypermethrin in neonatal and adult rats. Arch Toxicol 67: 510-513.

Casida JE and Quistad GB (1998) Golden age of insecticide research: Past, present, or future? Ann Rev Entomol 43: 1-16.

Dayal M, Parmar D, Dhawan A, Ali M, Dwivedi UN, Doehmer J, and Seth PK (1999) Induction of rat brain and liver cytochrome P450 1A1/1A2 and 2B1/2B2 isoenzymes by deltamethrin. Environ Toxicol Pharmacol 7: 169-178.

De Waziers I, Cugnenc PH, Yang CS, Leroux J-P, and Beaune PH (1990) Cytochrome P450 isozymes, epoxide hydrolase and glutathione transferases in rat and human hepatic and extrahepatic tissues. J Pharmacol Exp Therap 253: 387-394.

Gebremichael A, Chang AM, Buckpitt AR, Plopper CG, and Pinkerton KE (1995) Postnatal development of cytochrome P4501A1 and 2B1 in rat lung and liver: effect of aged and diluted sidestream cigarette smoke. Toxicol Appl Pharmacol 135: 246-253.

Glickman AH and Casida JE (1982) Species and structural variations affecting pyrethroid neurotoxicity. Neurobehav Toxicol Teratol 4: 793-799.

Gray AJ and Rickard J (1981) Distribution of radiolabel in rats after intravenous injection of a toxic dose of ${ }^{14} \mathrm{C}$-acid, ${ }^{14} \mathrm{C}$-alcohol, or ${ }^{14} \mathrm{C}$-cyano-labeled deltamethrin. Pest Biochem Physiol 16: $79-85$.

Heudorf U, Angerer J, and Drexler H (2004) Current internal exposure to pesticides in children and adolescents in Germany: Urinary levels of metabolites of pyrethroid and organophosphorus insecticides. Int Arch Occup Environ Health 77: 67-72. 


\section{MD \# 7807}

Hines RN and McCarver DG (2002) The ontogeny of human drug-metabolizing enzymes: Phase I oxidative enzymes. J Pharmacol Exp Therap 300: 355-360

Hoffman, H (1982). Absorption of drugs and other xenobiotics during development in experimental animals. Pharmacol Therap 16: 247-260.

Karanth S and Pope C (2000) Carboxylesterase and A-esterase activities during maturation and aging: Relationship to the toxicity of chlorpyrifos and parathion in rats. Toxicol Sci 58: 282289.

Kobayashi K, Urashima K, Shimada N, and Chiba K (2002) Substrate specificity for rat cytochrome P450 (CYP) isoforms: screening with cDNA-expressed systems of the rat. Biochem Pharmacol 63: 889-896.

Lawrence LJ and Casida, JE (1982) Pyrethroid toxicology: Mouse intracerebral structuretoxicity relationships. Pest Biochem Physiol 18: 9-14.

Mahmood B, Daood MJ, Hart C, Hansen TW, and Watchko JF (2001) Ontogeny of Pglycoprotein in mouse intestine, liver, and kidney. J Investig Med 49: 250-257

Morgan EW, Yan B, Greenway D, and Parkinson A (1994) Regulation of two rat liver microsomal carboxylesterase isozymes: Species differences, tissue distribution, and the effects of age, sex, and xenobiotic treatment of rats. Arch Biochem Biophys 315: 513-526.

Moser VC, Chanda SM, Mortensen SR, and Padilla S (1998) Age- and gender-related differences in sensitivity to chlorpyrifos in the rat reflect developmental profiles of esterase activities. Toxicol Sci 46: 211-222.

Naylor GP, and Harrison JD (1995) Gastrointestinal iron and cobalt absorption and iron status in young rats and guinea pigs. Hum Exp Toxicol 14: 949-954. 


\section{MD \# 7807}

Pope CN, Karanth S, Liu J, and Yan B (2005) Comparative carboxylesterase activities in infant and adult liver and their in vitro sensitivity to chlorpyrifos oxon. Reg Toxicol Pharmacol 42: 64-69.

Rickard J and Brodie ME (1985) Correlation of blood and brain levels of the neurotoxic pyrethroid deltamethrin with the onset of symptoms in rats. Pest Biochem Physiol 23: 143156.

Ruzo LO, Unai T, and Casida JE (1978) Decamethrin metabolism in rats. J Agric Food Chem 26: $918-925$.

Ruzo LO, Engel JL, and Casida JE (1979) Decamethrin metabolites from oxidative, hydrolytic, and conjugative reactions in mice. J Agric Food Chem 27: 725-731.

Satoh T and Hosokawa M (1998) The mammalian carboxylesterases: From molecules to functions. Ann Rev Pharmacol Toxicol 38: 257-288.

Sheets LP (2000) A consideration of age-dependent differences in susceptibility to organophosphorus and pyrethroid insecticides. Neurotoxicology 21: 57-63.

Sheets LP, Doherty JD, Law MW, Reiter LW, and Crofton KM (1994) Age-dependent differences in the susceptibility of rats to deltamethrin. Toxicol Appl Pharmacol 126: 186-190.

Soderlund DM and Casida JE (1977) Effects of pyrethroid structure on rates of hydrolysis and oxidation by mouse liver microsomal enzymes. Pest Biochem Physiol 7: 391-401.

Soderlund, DM, Clark, JM, Sheets LP, Mullin LS, Piccirillo VJ, Sargent D, Stevens JT, and Weiner, ML (2002) Mechanisms of pyrethroid neurotoxicity: Implications for cumulative risk assessment. Toxicology 171: 3-59.

Sonnier M and Cresteil T (1998) Delayed ontogenesis of CYP1A2 in the human liver. Eur J Biochem 251: 893-898. 
MD \# 7807

Srinivas R, Udikeri SS, Jayalakshmi SK, and Sreeramulu K (2004) Identification of factors responsible for insecticide resistance in Helicoverpa armigera. Compar Biochem Physiol (Part C) 137: 261-269.

Sterri SH, Berge G, and Fonnum F (1985) Esterase activities and soman toxicity in developing rat. Acta Pharmacol Toxicol (Copenh) 57: 136-140.

Whyatt RM, Camann DE, Kinney PL, Reyes A, Ramirez J, Dietrich J, Diaz D, Holmes D, and Perera FP (2002) Residential pesticide use during pregnancy among a cohort of urban minority women. Environ Health Perspec 110: 507-514.

Yanez L, Ortiz-Perez D, Batres LE, Borja-Aburto VH, and Diaz-Barriga F (2002) Levels of dichlorodiphenyltrichloroethane and deltamethrin in humans and environmental samples in malarious areas of Mexico. Environ Res (Sect A) 88: 174-181. 
MD \# 7807

\section{Footnotes}

Unnumbered footnote to the title

This project was supported by EPA STAR Grant \# R830800

This research has been reviewed by the National Health and Environmental Effects Research Laboratory, U.S. EPA, and approved for publication. Approval does not signify that the contents necessarily reflect the views and policies of the Agency, nor does mention of trade names or commercial products constitute endorsement or recommendation for use.

Figure 1 and the data of 90-d-old in Table 1 are reprinted from Toxicol. Appl. Pharmacol. Anand SS, Bruckner JV, Haines WT, Muralidhara S, Fisher JW, and Padilla S. Characterization of deltamethrin metabolism by rat plasma and liver microsomes. In press, 2005 with permission from Elsevier.

${ }^{1}$ Type I compounds do not contain a cyano group. Tremor and parathesias are the major signs of poisoning.

${ }^{2}$ Type II compounds contain a cyano group. Choreoathetosis and salivation are the major signs of poisoning.

\section{$\underline{\text { Reprint request: }}$}

Sathanandam S. Anand, $\mathrm{PhD}$

Department of Pharmaceutical and Biomedical Sciences, College of Pharmacy, University of Georgia, Athens, Georgia 30602, USA 
Tel \# 706-542-5401, Fax - 706-542-5358. Email: sanand@ rx.uga.edu

\section{Figure Legends:}

FIG. 1. Metabolism of deltamethrin (DLM). It is generally accepted that DLM is detoxified by CYP-mediated oxidation (dotted arrows) and esterase-mediated hydrolysis (solid arrows), followed by conjugation (dashed arrows). From Anand et al. (2005) with permission.

FIG. 2. Age-related deltamethrin (DLM) metabolism in rat plasma. Various concentrations of $\operatorname{DLM}(2,10,20,100$, or $200 \mu \mathrm{M})$ were incubated with $500 \mu \mathrm{l}$ of diluted plasma (PND10 - 40\% plasma; PND21 and $40-30 \%$ plasma) at $37^{\circ} \mathrm{C}$ for 120 (PND10 and 21) or 60 (PND40) min. Values represent mean \pm SE for 4 plasma samples (pooled or individual). The insert presents DLM metabolism following preincubation of diluted plasma with isoOMPA for $1 \mathrm{~h}$. Michaelis-Menten rate constants calculated by nonlinear regression are presented in Table 1.

FIG. 3. Age-dependent deltamethrin (DLM) metabolism by liver microsomal CaEs. A series of concentrations of DLM $(2,10,20,100$, and $200 \mu \mathrm{M})$ was incubated with diluted liver microsomes for 30 (PND21 and 40) and 60 (PND10) min at $37^{\circ} \mathrm{C}$. Values represent mean \pm SE for 4 hepatic microsomal preparations (pooled or individual liver samples). The insert presents DLM metabolism following preincubation of liver microsomes with isoOMPA for $1 \mathrm{~h}$. MichaelisMenten rate constants calculated by nonlinear regression are presented in Table 1.

FIG. 4. Age-dependent deltamethrin (DLM) metabolism by liver microsomal CYPs of 10-, 21and 40-d-old rats. Two, 10, 20, 100, or $200 \mu \mathrm{M}$ DLM were incubated with $1 \mathrm{ml}$ of liver microsmes (PND10 and $21-4 \mathrm{mg}$ protein/ml; PND40 - $1 \mathrm{mg}$ protein/ml) with or without 
MD \# 7807

$\mathrm{NADPH}(1.2 \mathrm{mM})$ for $30(\mathrm{PND} 10)$ or 15 (PND21 and 40$)$ min at $37^{\circ} \mathrm{C}$. Values present mean $\pm \mathrm{SE}$ for 4 different microsomal samples (pooled or individual liver samples). Michaelis-Menten rate constants calculated by nonlinear regression are presented in Table 1.

FIG. 5. Age-dependent changes in the intrinsic clearance $(\mathrm{Vmax} / \mathrm{Km})$ of $\mathrm{DLM}$ by liver microsomal and plasma CaEs and liver microsomal CYPs (A). Statistical comparison $(p \leq 0.05)$ was made between enzymatic pathways for each age. 'a' - significantly different from plasma $\mathrm{CaE}$ and ' $\mathrm{b}$ ' - significantly different from liver $\mathrm{CaE}$. Intrinsic clearance is expressed as percentage of adult values in panel B.

FIG. 6. Age-related changes in the blood DLM concentration versus time profiles in rats receiving $10 \mathrm{mg}$ DLM/kg po (Panel A). Treatment details are provided in the Materials and Methods. Results represent mean $\pm \mathrm{SE}$ ( $\mathrm{n}=3$ or 4 ). Mean blood DLM $\mathrm{AUC}_{0-6 \mathrm{~h}}$ and $\mathrm{AUC}_{0-12} \mathrm{~h}$ values are presented in panel B. Statistical comparison $(p \leq 0.05)$ was made between ages. 'a' significantly different from $10 \mathrm{~d}$ and ' $\mathrm{b}$ ' - significantly different from $21 \mathrm{~d}$. Panel C shows mean \pm $\mathrm{SE}(\mathrm{n}=3$ or 4 ) Cmaxs. * indicates statistically significant difference from PND10 group (P $\leq 0.05)$

Fig. 7. Correlation of internal exposure to DLM (blood AUCs) with salivation and tremors. The total score was calculated by summing the 1-, 2-, 3-, 4- and 6-h scores of each toxic sign for each age-group. Correlation coefficient $\left(\mathrm{r}^{2}\right)$ between AUCs and severity of salivation is 0.87 and between AUCs and severity of tremors is 0.90 
MD \# 7807

Table 1. Age-dependent in vitro metabolic rate constants for DLM metabolism

\begin{tabular}{|c|c|c|c|c|c|}
\hline \multirow{2}{*}{ Enzyme } & \multirow{2}{*}{$\begin{array}{l}\text { Enzyme } \\
\text { kinetics }\end{array}$} & \multicolumn{4}{|c|}{ Ages (days) } \\
\hline & & 10 & 21 & 40 & 90 \\
\hline \multirow{3}{*}{ Plasma CaE } & $\mathrm{Vmax}$ & $51.38 \pm 7.51$ & $87.20 \pm 18.72$ & $240.73 \pm 58.77^{\mathrm{ab}}$ & $325.30 \pm 53.4^{\mathrm{ab}}$ \\
\hline & $\mathrm{Km}$ & $142.20 \pm 27.41$ & $117.41 \pm 31.93$ & $115.26 \pm 22.07$ & $165.40 \pm 41.90$ \\
\hline & $\begin{array}{l}\text { Intrinsic } \\
\text { clearance }\end{array}$ & $0.39 \pm 0.06$ & $0.80 \pm 0.09^{\mathrm{a}}$ & $2.28 \pm 0.56^{\mathrm{ab}}$ & $2.4 \pm 0.4^{\mathrm{ab}}$ \\
\hline \multirow{3}{*}{ Liver CaE } & $V \max$ & $23.78 \pm 3.99$ & $114.25 \pm 9.01^{\mathrm{a}}$ & $296.65 \pm 55.18^{\mathrm{ab}}$ & $1981.80 \pm 132.30^{\mathrm{abc}}$ \\
\hline & $\mathrm{Km}$ & $73.69 \pm 14.74$ & $74.76 \pm 15.86$ & $118.78 \pm 21.20$ & $172.50 \pm 22.50^{\mathrm{ab}}$ \\
\hline & $\begin{array}{l}\text { Intrinsic } \\
\text { clearance }\end{array}$ & $0.34 \pm 0.05$ & $1.77 \pm 0.38^{\mathrm{a}}$ & $2.53 \pm 0.19^{\mathrm{a}}$ & $12.00 \pm 5.90^{\mathrm{abc}}$ \\
\hline \multirow{3}{*}{ Liver CYP } & $\mathrm{Vmax}$ & $185.30 \pm 12.16$ & $381.33 \pm 28.67^{\mathrm{a}}$ & $1231.73 \pm 144.79^{\mathrm{ab}}$ & $2611.30 \pm 134.10^{\mathrm{abc}}$ \\
\hline & $\mathrm{Km}$ & $37.79 \pm 4.26$ & $23.40 \pm 3.23$ & $34.15 \pm 5.54$ & $74.90 \pm 5.90^{\mathrm{abc}}$ \\
\hline & $\begin{array}{l}\text { Intrinsic } \\
\text { clearance }\end{array}$ & $4.99 \pm 0.32$ & $16.99 \pm 1.85^{\mathrm{a}}$ & $38.45 \pm 7.03^{\mathrm{ab}}$ & $35.5 \pm 2.90^{\mathrm{ab}}$ \\
\hline
\end{tabular}

Results are expressed as mean $\pm \mathrm{SE}(\mathrm{n}=4)$. Vmax values are expressed as $\mathrm{nmol} / \mathrm{h} / \mathrm{g}$ liver or $\mathrm{ml}$ plasma; $\mathrm{Km}$ values are expressed as $\mu \mathrm{M}$; intrinsic clearance $(\mathrm{Vmax} / \mathrm{Km})$ values are expressed as $\mathrm{h}^{-1}$. Statistical comparison $(p \leq 0.05)$ was made between different ages for each parameter for each enzymatic pathway. ' a' - significantly different from PND10, 'b' - significantly different from PND21 and 'c' - significantly different from PND40. Anand et al. (2005) is the source of the PND90 values. 
MD \# 7807

Table 2. Age-dependent toxic signs following DLM administration

\begin{tabular}{|c|c|c|c|c|c|c|c|c|c|c|}
\hline Time (h) & \multicolumn{2}{|c|}{1} & \multicolumn{2}{|c|}{2} & \multicolumn{2}{c|}{3} & \multicolumn{2}{c|}{4} & \multicolumn{2}{c|}{6} \\
\hline Age (days) & $\mathrm{S}$ & $\mathrm{T}$ & $\mathrm{S}$ & $\mathrm{T}$ & $\mathrm{S}$ & $\mathrm{T}$ & $\mathrm{S}$ & $\mathrm{T}$ & $\mathrm{S}$ & $\mathrm{T}$ \\
\hline 10 & 2.75 & 1 & 2.5 & 1.5 & 2.5 & 2.25 & 3 & 2.5 & 3 & 3 \\
\hline 21 & 2.25 & 1 & 2.5 & 1 & 2.75 & 1.25 & 3 & 1.75 & 3 & 2 \\
\hline 40 & 1 & 0 & 2 & 0 & 0.75 & 0 & 0 & 0 & 0 & 0 \\
\hline 90 & 0.5 & 0 & 1.25 & 0 & 0 & 0 & 0 & 0 & 0 & 0 \\
\hline
\end{tabular}

Male SD rats were given with $10 \mathrm{mg}$ DLM/kg by gavage. While 10- and 21-d-old rats showed salivation (S) and tremors (T), 40- and 90-d-old rats experienced only transient salivation.

Sustained toxic signs resulted in $100 \%$ mortality between $6-8 \mathrm{~h}$ in 10 -d and between $12-16 \mathrm{~h}$ in 21-d rats. All the 40- and 90-d rats survived. The severity of the signs was assessed using subjective scoring as follows: 0 - no appearance of signs, 1 - mild; 2 - moderate; and 3 - severe. The scale is defined in the Materials and Methods. Mean values of 4 rats are presented. 

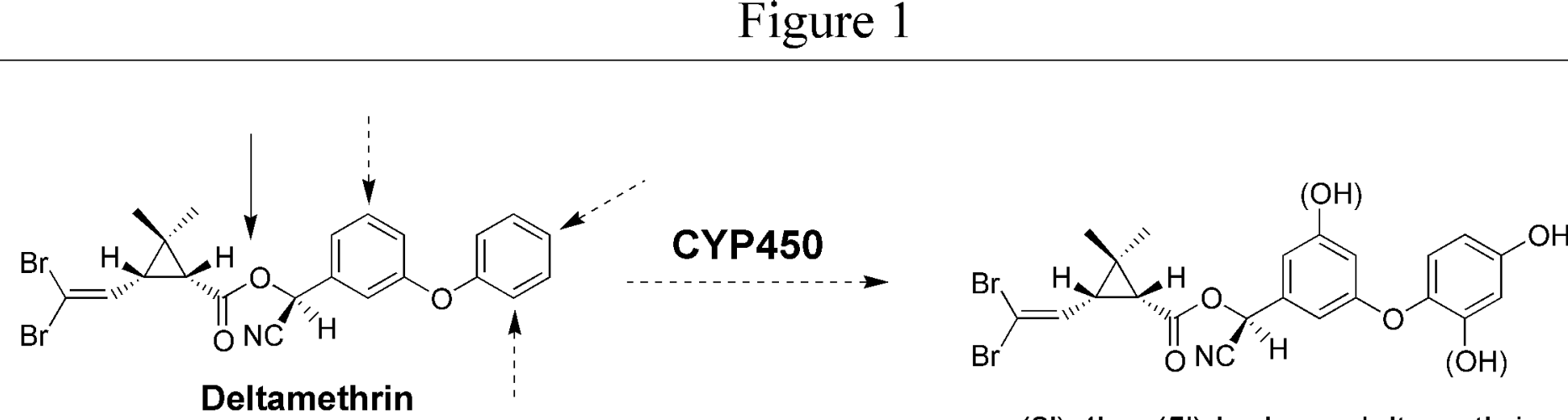

$\left(2^{\prime}\right), 4^{\prime}$ or (5')-hydroxy-deltamethrin

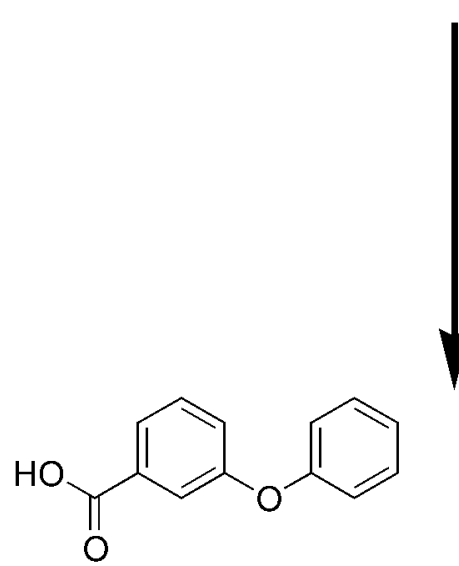

3-Phenoxybenzoic acid

\section{Esterase}

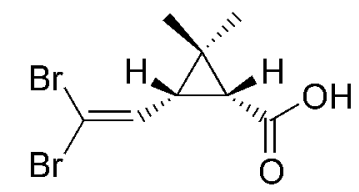

3-(2,2-Dibromovinyl)-2,2-dimethylcyclopropanecarboxylic acid

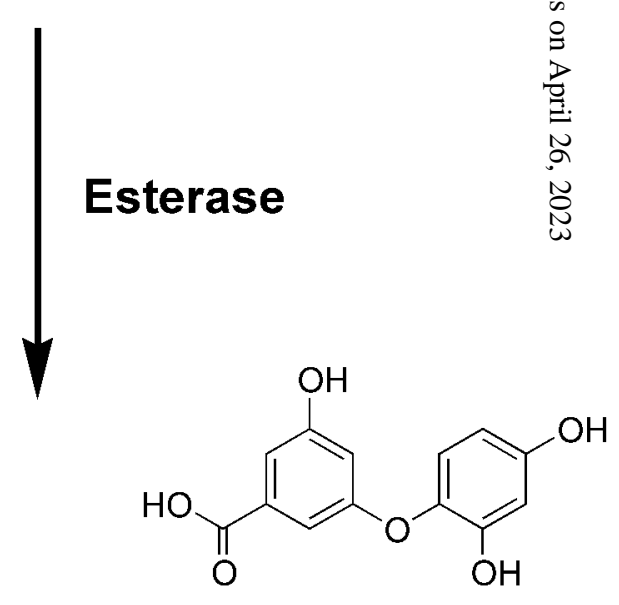

3- $\left(2^{\prime}, 4^{\prime}\right.$ or 5'-Hydroxyphenoxy)benzoic acid
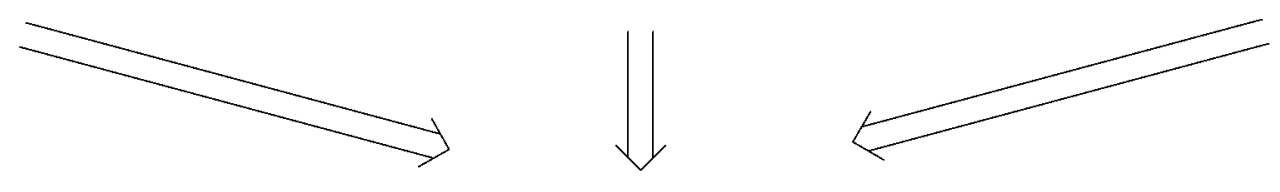

Sulfate and glucuronide conjugation 
Figure 2

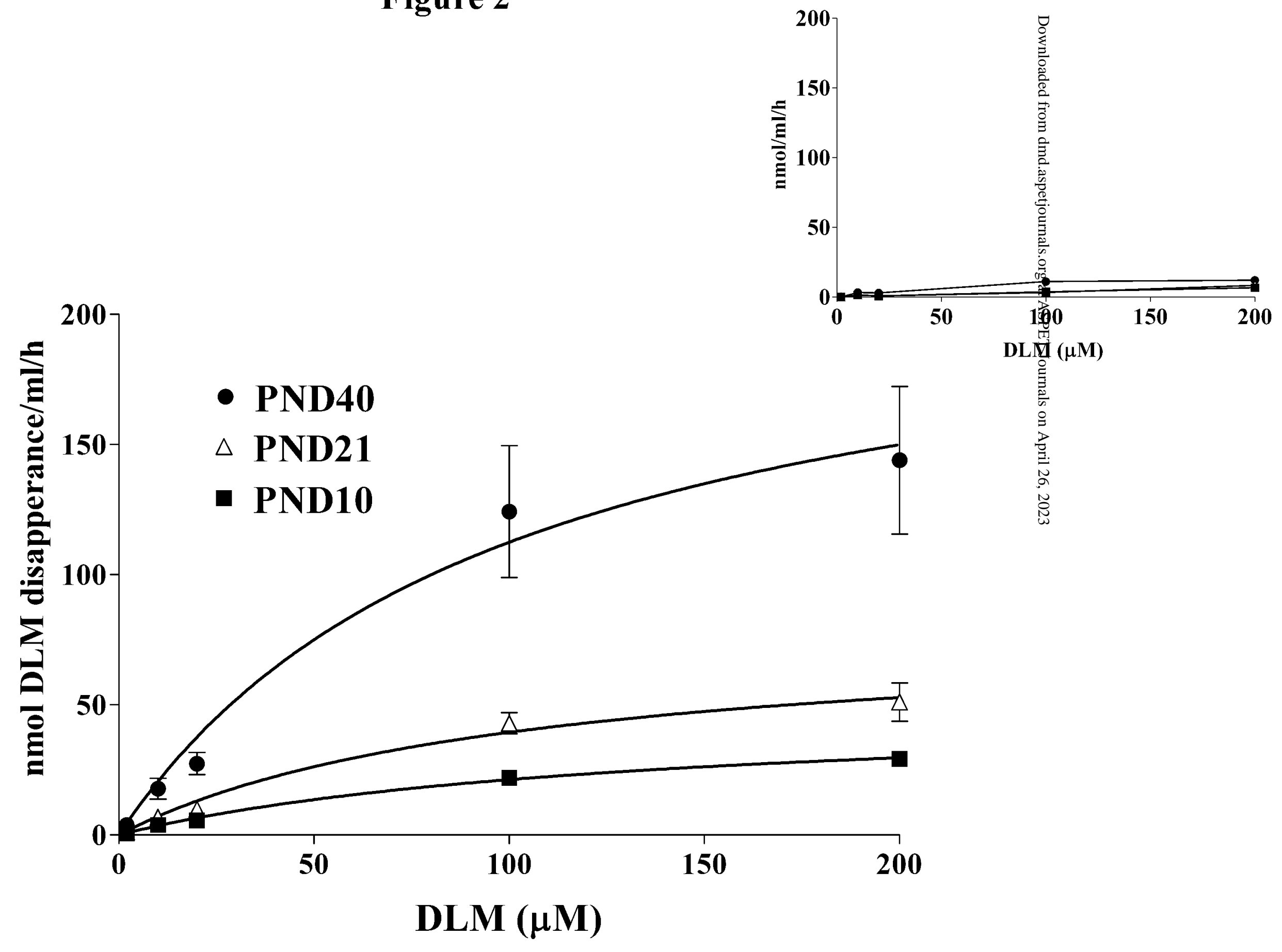




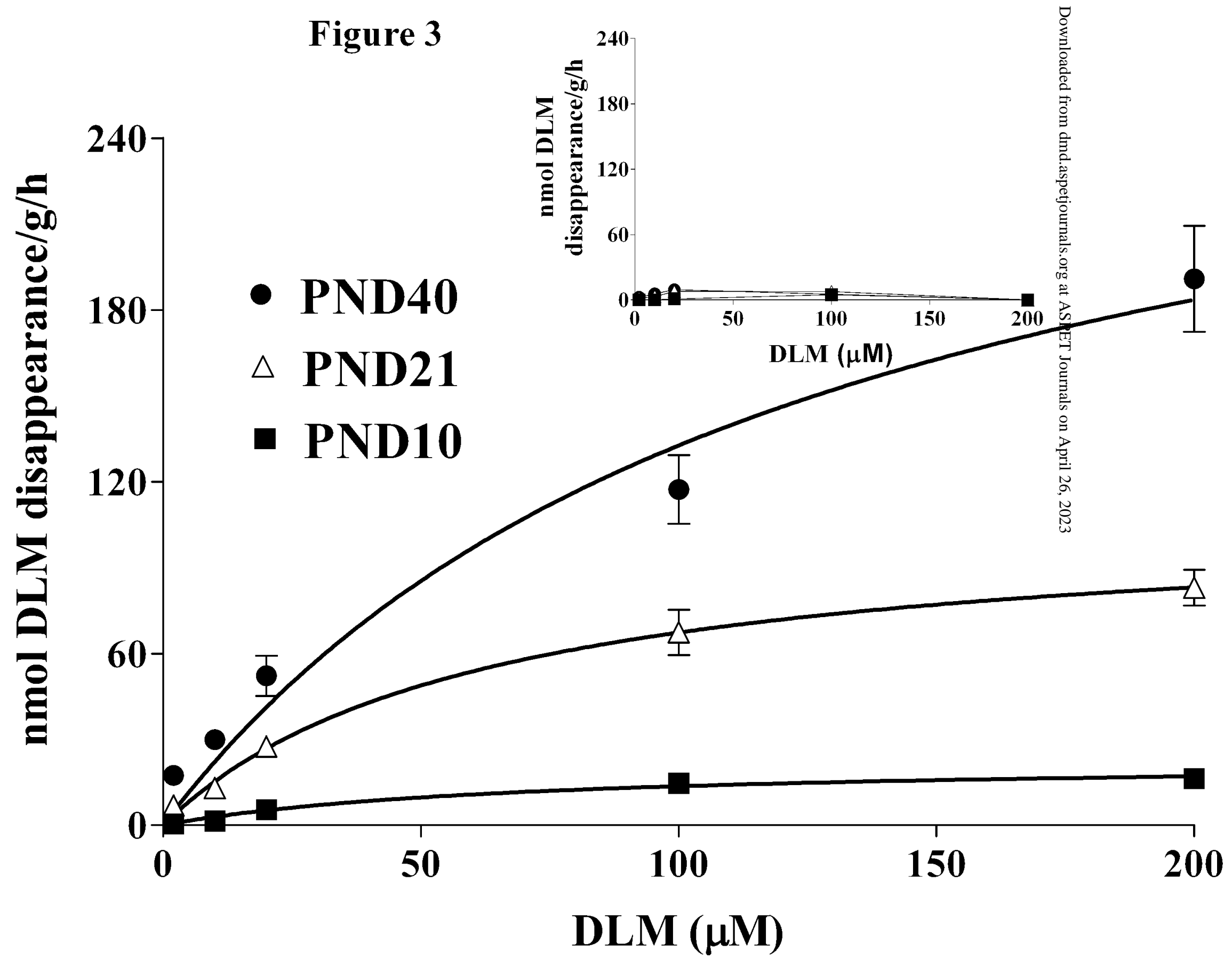


Figure 4

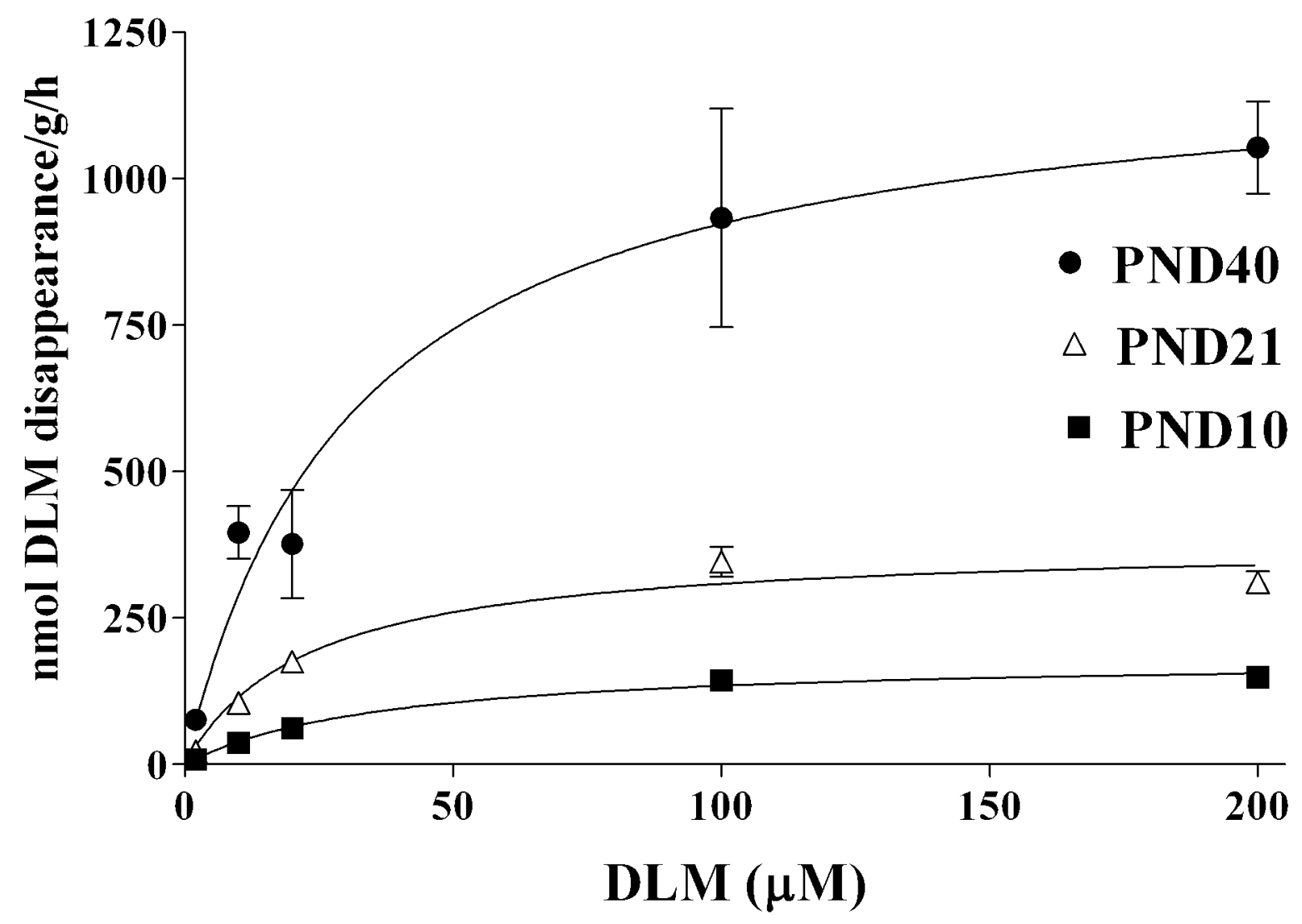


Figure 5
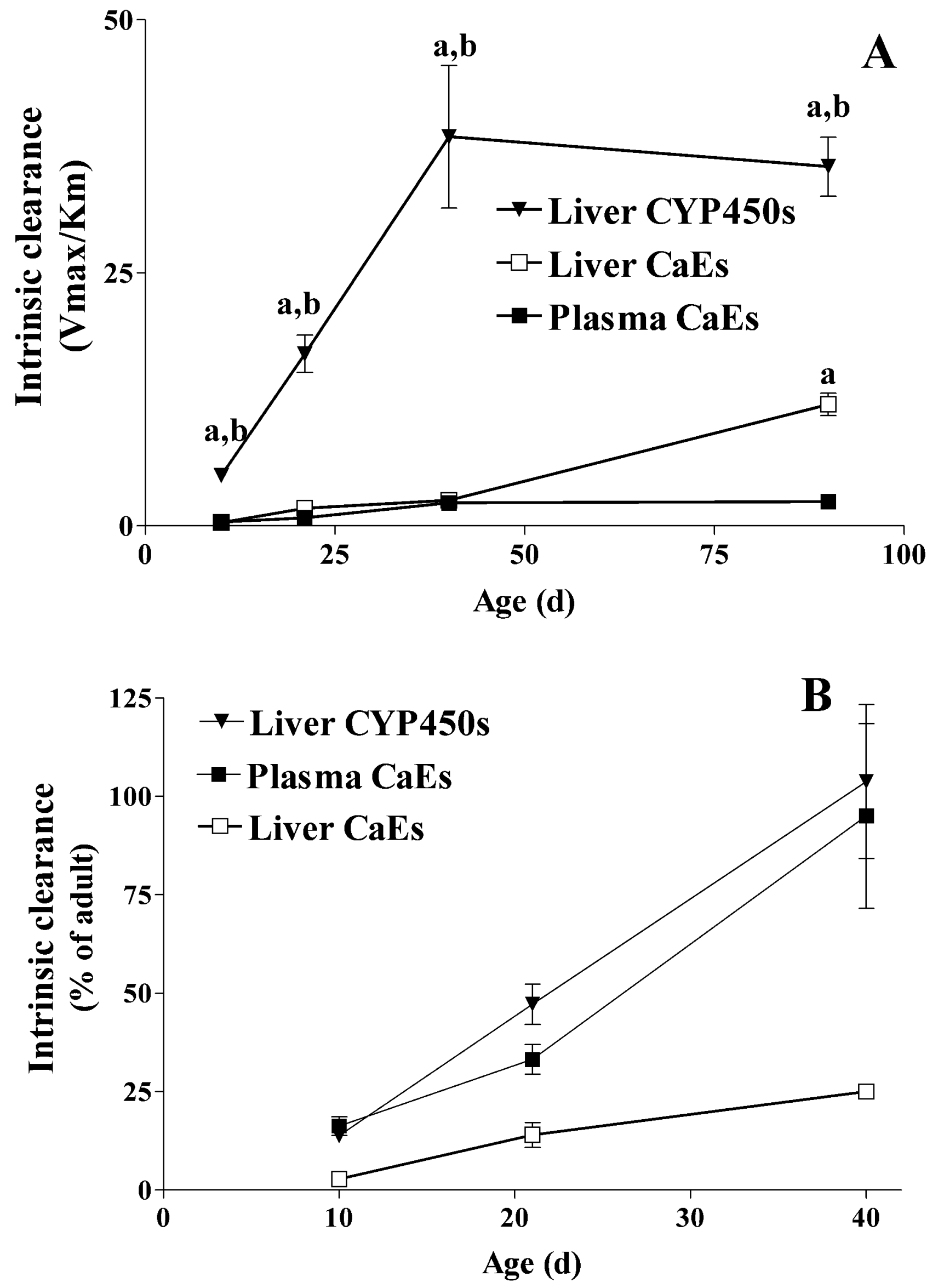
Figure 6
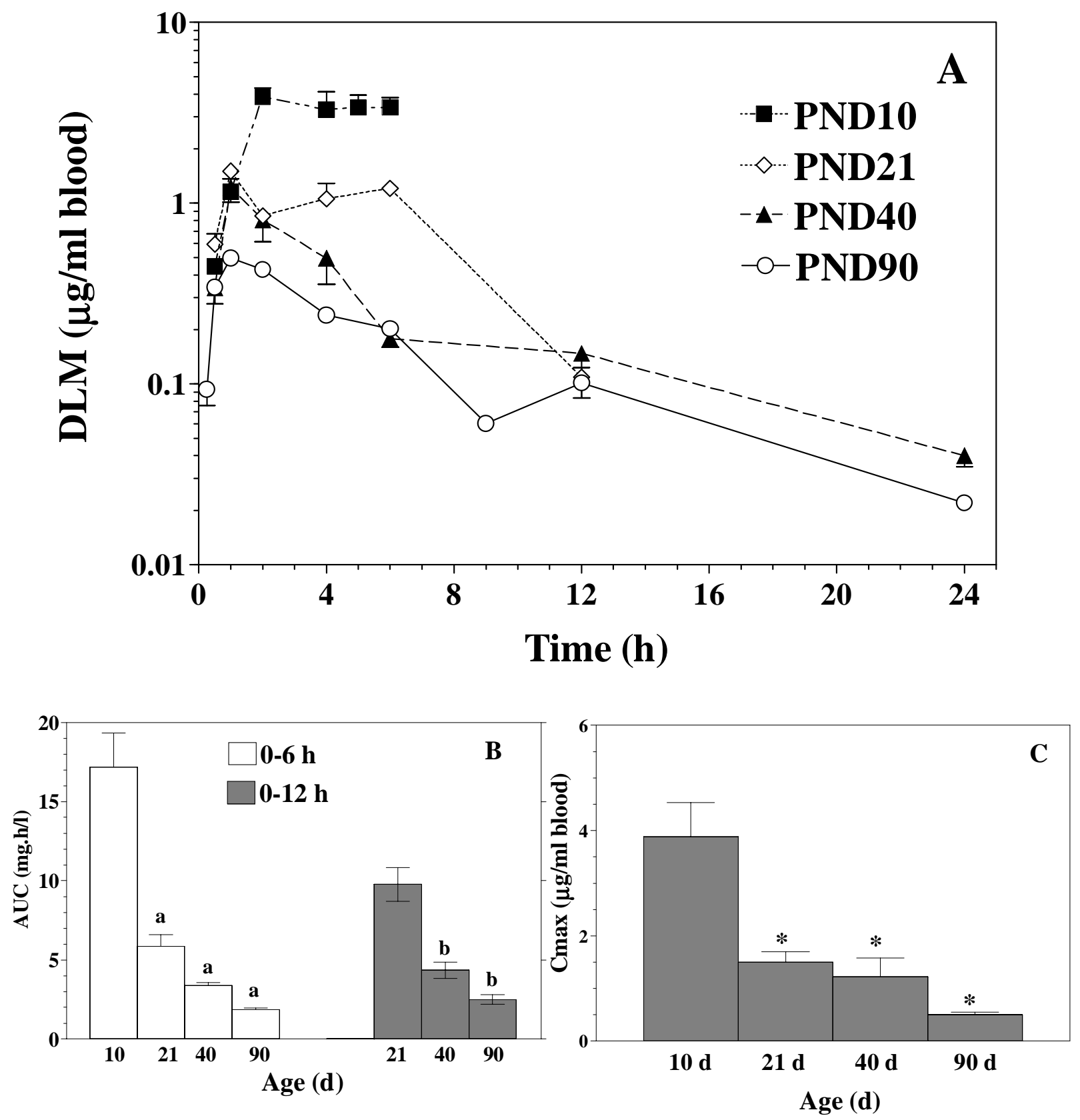

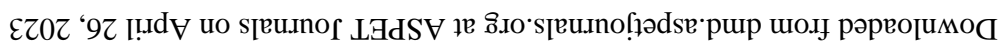


Figure 7

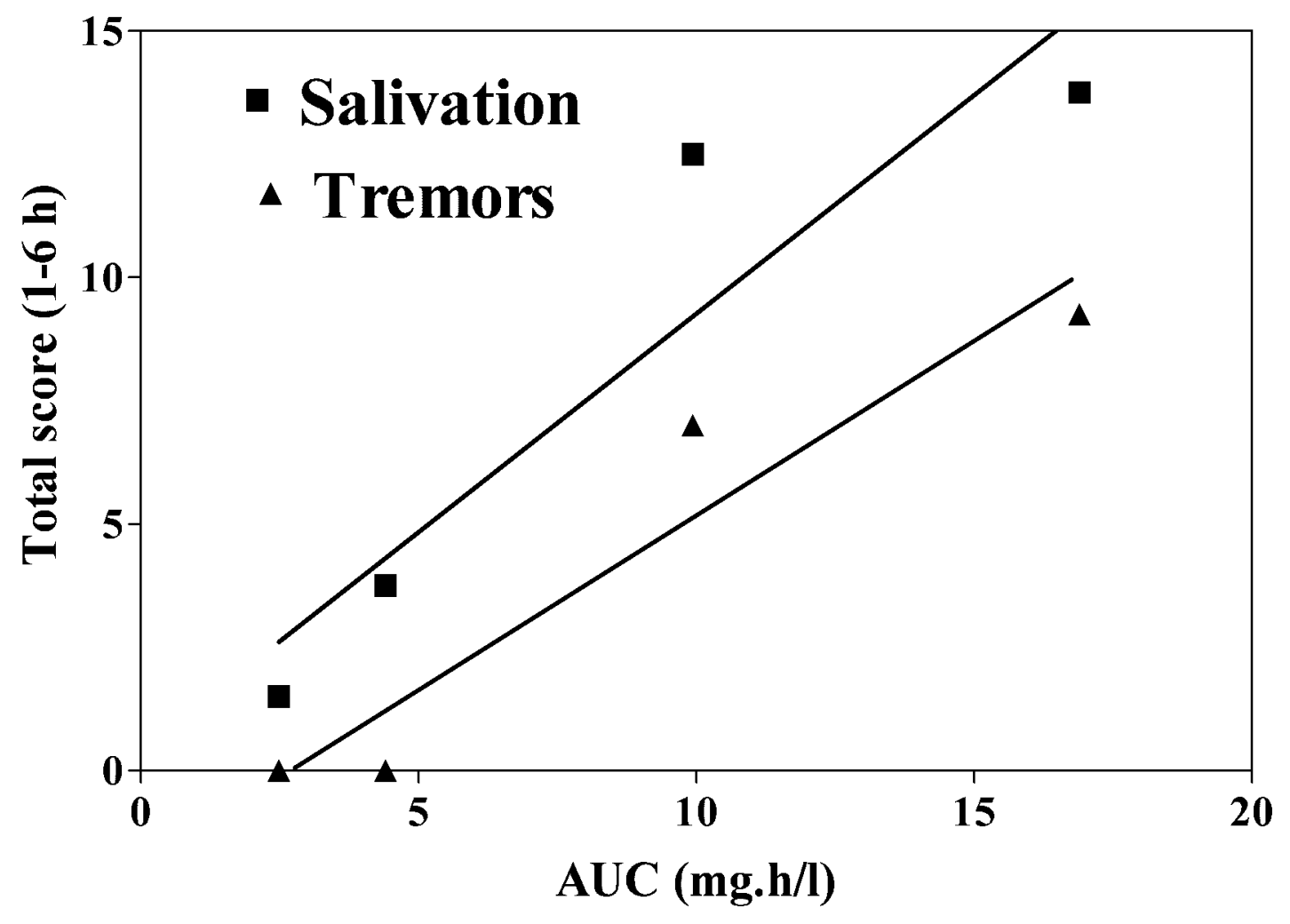

